\title{
Dehydration in Children with Respiratory Tract Infections in a Pediatric Emergency Department of a Tertiary Hospital
}

\section{Rebeca Sosa MD' ${ }^{1}$, Luis Alonso Mata-Perez Md ${ }^{2}$, Manuel E. Soto-Quiros Md ${ }^{3}$, Manuel E. Soto-Martinez $\mathrm{Md}^{4}$ and Adriana Yock-Corrales $\mathrm{Md}^{2}$}

1. Pediatric Department. Hospital upala. Ccss. Alajuela, Costa Rica

2. Emergency Department. Hospital Nacional de Niños “Dr. Carlos Sáenz Herrera”. CCSS. San José, Costa Rica

3. Hospital Cima San José. San José, Costa Rica

4. Respiratory Department. Hospital Nacional de Niños “Dr. Carlos Sáenz Herrera”. Ccss. San José, Costa Rica

\begin{abstract}
Backgrounds: Dehydration is a common finding the Emergency Department(ED). The main cause of dehydration in the pediatric population is acute gastroenteritis, but it can be present with other illness such as respiratory infections. The aim of this study was to determine the prevalence of dehydration in patients presenting with lower respiratory tract infection (LRTI).

Methods: Prospective observational study of patients with LRTI admitted in the ED in a period of three-months. Patients with LRTI were included and assessed with the Clinical Dehydration Scale (CDS) to determine clinical dehydration. Patients were weighted on admission and 24-hours after admission to determine weight change after fluid management.

Results: 88 patients with LRTI were included. A total of 23(26.1\%) patients presented a degree of dehydration according to the CDS scale. Comparing weight changed on admission and 24-hours later 55.6\% had an increased weight. When comparing the grade of dehydration with the CDS scale vs increased weight changed at 24-hours after fluid management, it was statically significant for patients 6 months- 1 year(23\% vs 64\%; p value 0.01 ), 1-2 years $(25 \%$ vs $50 \%$; p value 0.05 ) and $>2$ years ( $16 \%$ vs $50 \%$;p value 0.03 ). The most common clinical finding was mild dehydration in 22 patients and moderate/severe in only 1 patient.

Conclusions: This is one of the few studies of dehydration in illness not related to gastroenteritis. The key finding of this study was that LRTI in some of the patients were associated with certain degree of dehydration. Not all patients with dehydration were detected using clinical findings and this difference was found using weight changed.
\end{abstract}

Corresponding author: Adriana Yock-Corrales, MD. Emergency department, hospital nacional de niños "dr. Carlos sáenz herrera”. San josé, costa rica. Po box: 957-1100. Phone: (506) 2523-3600, ext 4161. Email: adriyock@gmail.com

Received: January 23, 2020, Accepted: February 02, 2020, Published: February 07, 2020

Keywords: Poisson Regression, Logistics Regression, Geographical Information System, Electro Magnetic Field, Radiation, Mobile Towers.

\section{Introduction}

Dehydration is a physiologic response to a variety of ill- ness where the main result is a negative fluid balance. There are many mechanisms such as poor oral intake, 
increase of renal or gastrointestinal losses or due to a systemic response such as sepsis [1]. Dehydration is a common clinical finding in patients during evaluation in a Pediatric Emergency Department(ED). Themain cause of dehydration worldwide in the pediatric population is acute gastroenteritis, but it can be present with other illness. In the pediatric population, dehydration is a main complain on ED presentation and represents 385 000 patients per year, being acute gastroenteritis the main cause for dehydration [1]. The symptoms and signs according to the degree of dehydration can vary from being asymptomatic to hypovolemic shock [2]. The gold standard to determine the presence of dehydration is the weight change after adequate rehydration. The dehydration scales more often used in clinical practice are Gorelick scale (created at the children Hospital of Philadelphia) and the Clinical Dehydration Scale (CDS) (created at the Hospital for Sick Children in Toronto); the last one is the only validated scale and gold standard used in North America. None of these scales have been validated in medium or low-income countries [3-5]. After rehydration, weight change is the best parameter to categorize the severity of dehydration, but in the emergency setting is not always possible to calculate this because of difficulties in getting weights on admission. In the ED we based our assessment in clinical scales like the ones described previously [10]. The presence of dehydration is sometimes associated with electrolyte disturbances. In 2004 the CDC published a study where 182 patients were admitted for dehydration, and $48 \%$ presented at least one electrolyte disturbance. The main electrolyte disturbances documented werehyponatremia (28\%) hypoglycemia (9\%) and hypokalemia (6\%) [5]. Many other diseases had been associated with dehydration besides acute gastroenteritis, such as bronchiolitis, pneumonia, meningitis and urinary tract infections [15]. LRTI is a common pathology in the pediatric emergency departments and the leading cause of hospitalization during the first year of life, resulting in a major cause of morbidity and mortality $[1,6]$. The relationship between LRTIs and prevalence of dehydration is unknown; and is one of the objectives to address in this study, the only study found in the literature was one from Costa Rica by Dr. Mohs et al in 1986. The main results of this study was a prevalence of dehydration of $26.4 \%$ in 140 patients, all of them mild-moderate dehydration according to clinical score. Eighty-one percent of those with dehydration had normal serum sodium and nineteen percent mild hyponatremia [8]. The main purpose of this study was to describe the relationship between LRTIs and degree of dehydration; and to identify the presence of electrolyte changes. The results of this study can help physicians to make decisions regarding the management of LTRI and its association with dehydration.

\section{Methods \\ Study Design}

This was a prospective observational study of children with the diagnosis of LRTIs at the Hospital Nacional de Niños "Dr. Carlos Saenz Herrera". The hospital is the only tertiary referral and teaching pediatric center in the country, with $\sim 350$ beds and around 115000 annual emergency department admissions. The study was approved by the hospital Institutional Ethical Committee and permission was obtained to review clinical charts. The study was performed during a 3-month period from July to September of 2015. The inclusion criteria were children aged 1 month to 36 months of age with the diagnosis of LRTI including pneumonia, bronchiolitis, asthma, recurrent wheeze and croup that had oxygen requirement and needed hospital admission. The exclusion criteria were the presence of diarrhea because is an already known cause of dehydration, previous fluid replacement in another health facility because will alter the degree hydration status when the patient arrive to the ED and patients without weight measure during the initial approached. Vomiting wasn't excluded because is a symptom usually present with cough and LRTI, even if that is a common cause of dehydration. Once the patient was admitted to the hospital, they were treated according to the hospital standard protocol related to their diagnosis. The total number of patients admitted with a LRTI during the study period was of 500 and the total included patients were of 88 patients, due to the schedule they where admitted and result of the exclusion criteria. . The percent of weight change in patients that needed rehydration, which is the gold standard, and the Clinical Dehydration Scale (CDS) were used to assess dehydration. Percent weight change with rehydration 
was calculated by (rehydration weight - admission weight)/rehydration weight $\times 100 \%$. Is classified in percentage been no dehydration less than 3\%, 3-6\% mild and more than $6 \%$ is moderate to severe. Dehydration is defined in our study with the weigh change after hydration been difference more than $>3 \%$ and $>1$ point based of clinical classification of the CDS scale.

\section{Data Collection and Processing}

A standard data collection form was used to obtain information from clinical charts. The tool was completed following a review of the medical charts. Patients were included only during weekdays from $7 \mathrm{am}$ to $3 \mathrm{pm}$ where we had research assistant. Data was extracted from electronic ED records, admission and progress notes as well as laboratory reports. Data collected included demographics, age, past medical history, hospital stay, weight measurement on admission and 24 hours after admission, CDS dehydration score in Emergency department, electrolytes on admission, symptoms and signs, investigations, interventions and complications. Presenting signs and symptoms were extracted according to the first ED notes.

\section{Data Analysis}

A statistical analysis was performed using Epi info 3.4.1 (CDC-2007) and Stata 12 (StataCorp, College Station, TX). Presenting symptoms and signs were analyzed descriptively. Analyses was performed on the total number of patients and presented as percentages with corresponding 95\% confidence intervals. Continuous variables were presented as mean and SD (normal distribution) or median and interquartile range (IQR) (non-normal distribution). We made comparisons between the groups (Dehydration versus No Dehydration) using logistic regression for binary outcomes and linear regression for continuous outcomes. Results are presented as differences between proportions and odds ratios (ORs) for binary outcomes and mean differences for continuous outcomes.

\section{Results}

Eighty-eight patients were included in the study. Patients ranged from 1 month to 36 months of age with median of 14.5 months (DS 9.9). The majority of patients were male (57\%). Mean days of hospitalization was 4.3 days (DS 3.3) with a range of 1 to 20 days. Seventy-nine percent have a known comorbidity; the commonest was recurrent wheeze (OBTENIDA COMO UN DATO DE HISTORIA CLINICA) in $31.8 \%$ of patients, followed by prematurity in $18.1 \%$ and asthma in $16.1 \%$. (Table 1).

\begin{tabular}{|l|l|}
\hline Patient Characteristics & Number (\%) \\
\hline Sex & $\mathrm{N}=88$ \\
\hline Male & $50(57)$ \\
\hline Female & $38(43)$ \\
\hline Past Medial History & $28(31.8)$ \\
\hline Recurrent wheeze & $16(18.1)$ \\
\hline Prematurity & $14(16.1)$ \\
\hline Asthma & $9(9.1)$ \\
\hline Malnutrition & $3(3.4)$ \\
\hline $\begin{array}{l}\text { Others (Cardiac disease } \\
\text { and Neuropathy) }\end{array}$ & $23(26.2)$ \\
\hline $\begin{array}{l}\text { Referred from other } \\
\text { health center }\end{array}$ & $59(67)$ \\
\hline Previous Consultation
\end{tabular}

Table 1: Demographic and Characteristics of patients with lower respiratory tract infection admitted in the ED.

The majority of patients (67\%) had at least a previous consultation in a health facility. Thirty-four (38.6\%) patients had a previous hospital admission in the last 6 months. No signs of dehydration were reported in $73.8 \%$ of patients using the CDS scale, $25.1 \%$ presented mild dehydration and only one patient present moderate to severe dehydration. The was no significant difference between the mean age in the dehydration 13.9 months and non-dehydration 15.6 groups ( $\mathrm{p}$ value $=0.21$ ). The patients that were classified as dehydrated and it's severity by the CDS score, were confirmed by the increased of weight after IV fluids maintenance and adequate fluid replacement ( $\mathrm{p}$ value $=0.01$ ). Fifty five percent of the patients had an increased weight when compare with the initial weight on admission and weight 24 hours after admission. As shown in table 2, patients in the study were divided by aged groups and a comparison was made between the ones that were classified as dehydrated according to the CDS scale and the ones that had an increased in weight 24 hours after admission. As shown in Table 2, patients in the study 


\begin{tabular}{|l|l|l|l|l|l|}
\hline Age & $\begin{array}{l}\text { Total } \\
\mathrm{n}(\%)\end{array}$ & $\begin{array}{l}\text { Score } \\
\text { CDS } \\
\mathrm{n}(\%)\end{array}$ & $\begin{array}{l}\text { Weight } \\
\text { Change } \\
\mathrm{n}(\%)\end{array}$ & OR (CI 95\%) & P value \\
\hline $\begin{array}{l}<3 \\
\text { Months }\end{array}$ & $10(11.3)$ & $3(3.4)$ & $5(5.6)$ & $0.4(0.04-3.6)$ & 0.36 \\
\hline $\begin{array}{l}\text {-6 } \\
\text { Months }\end{array}$ & $15(17)$ & $6(6.8)$ & $9(10.2)$ & $0.4(0.08-2.3)$ & 0.2 \\
\hline $\begin{array}{l}\text { 6m-1 } \\
\text { Year }\end{array}$ & $17(19.3)$ & $4(4.5)$ & $11(12.5)$ & $0.190 .02-0.9)$ & 0.01 \\
\hline $1-2$ Year & $28(31.8)$ & $7(7.9)$ & $14(16)$ & $0.3(0.09-1.1)$ & 0.05 \\
\hline$>2$ Year & $18(20.4)$ & $3(3.4)$ & $9(10.2)$ & $0.2(0.02-1.1)$ & 0.03 \\
\hline Total & $88(100)$ & $23(26.1)$ & $48(54.5)$ & $0.3(0.140 .58)$ & 0.001 \\
\hline
\end{tabular}

Table 2: Comparison of dehydrated patients with the CDS scale and patients with increased weight 24 -hours after admission according to age group.

were divided by aged groups and a comparison was made between the ones that were classified as dehydrated according to the CDS scale and the ones that had an increased in weight 24 hours after admission. From the total of $17(19.3 \%)$ patients aged from 6 months to 12 months old, 4 were dehydrated according to the CDS scale but 11 had an increased weight 24 hours after admission ( $\mathrm{p}$ value $=0.01$ ). Similar situation was reported for older patients. The time from onset of symptoms until admission in the ED was recorded in all patients and less than 3 days was reported in 53 (60.2\%) patients. Respiratory distress was the main complain in $66(75 \%)$ patients. In regard to the initial clinical findings, the most common associated symptom was vomiting that was present in a $39 \%$ of the dehydrated patients versus $10.7 \%$ of the non-dehydrated ( $\mathrm{p}$ value $=0.002$ ). Poor oral intake was present in $74 \%$ of the dehydrated patients and in a $50.7 \%$ of the non-dehydrated (p value $=0.05)$ as shown in Table 3.Forty-six $(52.2 \%)$ patients had serum electrolyte analysis. Hyponatremia was reported in $23.9 \%$ of the patients, the majority had mild hyponatremia and only one patient moderate hyponatremia with no clinical consequences [11]. From those patients having hyponatremia only 7 patients were reported with dehydration according to the CDS scale. In 61(69.3\%) patients a viral immunofluorescence (IFV) was performed: $18 / 61(29.5 \%)$ had a positive Metapneumovirus, 6/61 (9.8\%) patients had a positive Respiratory Syncytial virus and 3/61 (4.9\%) had a positive parainfluenza. In regard to treatment, only $6.8 \%$ of the patients had intravenous fluids administration.

\begin{tabular}{|l|l|l|l|l|l|}
\hline Variable & $\begin{array}{l}\text { Dehy- } \\
\text { drated } \\
\mathbf{n}(\%)\end{array}$ & $\begin{array}{l}\text { Non De- } \\
\text { hydrated } \\
\mathbf{n}(\%)\end{array}$ & OR & CI (95\%) & P Value \\
\hline Total & $23(26.1)$ & $65(73.8)$ & - & - & - \\
\hline Vomiting & $9(39.1)$ & $7(10.7)$ & 5.3 & $1.4-19.7$ & 0.002 \\
\hline $\begin{array}{l}\text { Sunken } \\
\text { eyes }\end{array}$ & $2(8.7)$ & - & - & - & 0.01 \\
\hline Fever & $17(74)$ & $35(53.8)$ & 1.5 & $05-5.5$ & 0.36 \\
\hline $\begin{array}{l}\text { Poor Oral } \\
\text { Intake }\end{array}$ & $17(74)$ & $33(50.7)$ & 2.74 & $0.8-9.5$ & 0.05 \\
\hline $\begin{array}{l}\text { Hyporex- } \\
\text { ia }\end{array}$ & $8(34.7$ & $25(38.4)$ & 0.85 & $02-2.5$ & 0.75 \\
\hline $\begin{array}{l}\text { Wheez- } \\
\text { ing }\end{array}$ & $17(74)$ & $45(69.2)$ & 1.25 & $0.3-4.4$ & 0.67 \\
\hline
\end{tabular}
dehydration on admission according to the CDS scale.

Fifty-six patients had maintenance fluid replacement because patients were either too sick to have oral intake or the patient was admitted in hours were food was not available. In $65.4 \%$ of the patients of the dehydrated group and in $53.8 \%$ from the non-dehydrated group had maintenance fluids as seen in table 4 .

\begin{tabular}{|l|l|l|l|l|l|}
\hline Variable & $\begin{array}{l}\text { Dehydra- } \\
\text { tion } \\
\mathbf{N}: 23 \\
\mathbf{n}(\%)\end{array}$ & $\begin{array}{l}\text { Non de- } \\
\text { hydrated } \\
\text { N: 65 } \\
\mathbf{n}(\%)\end{array}$ & OR & CI (95\%) & P value \\
\hline $\begin{array}{l}\text { Weight } \\
\text { Gain }\end{array}$ & $16(69.5)$ & $32(49.2)$ & 2.35 & $0.78-7.6$ & 0.09 \\
\hline $\begin{array}{l}\text { Rehy- } \\
\text { dration } \\
\text { fluids }\end{array}$ & $6(26.1)$ & - & - & - & $<0.001$ \\
\hline $\begin{array}{l}\text { Main- } \\
\text { tenance } \\
\text { Fluids }\end{array}$ & $14(65.4)$ & $35(53.8)$ & 1.6 & $0.54-4.5$ & 0.34 \\
\hline $\begin{array}{l}\text { Nebuliza- } \\
\text { tion }\end{array}$ & $16(69.5)$ & $52(80)$ & 0.5 & $0.17-2$ & 0.3 \\
\hline $\begin{array}{l}\text { High flow } \\
\text { Nasal } \\
\text { cannula }\end{array}$ & $6(26.1)$ & $12(18.4)$ & 1.47 & $0.4-5$ & 0.49 \\
\hline
\end{tabular}

Table 4: Treatment administration during admission in the Emergency Department in patients with lower respiratory tract infection according to hydration status with CDS scale.

The most common diagnosis was bronchiolitis in a $53.4 \%$. The main treatment used for the primary pathology were nebulized treatment in $77.2 \%$ of the patients with salbutamol in the majority of the patients (97\%). Oxygen was administered in all the patients, 
antibiotic was administered in 53(60.2\%) and the most common was amoxicillin in 29 patients, steroids in $39(44.3 \%)$ patients, $3(3.4 \%)$ required respiratory support and 8 (9\%) were admitted in the intensive care unit. Main diagnoses are shown in table 5.

\begin{tabular}{|c|c|c|c|c|c|c|}
\hline $\begin{array}{l}\text { Diagno- } \\
\text { sis }\end{array}$ & $\begin{array}{l}\text { Total } \\
\text { N(\%) }\end{array}$ & $\begin{array}{l}\text { Dehy- } \\
\text { drated } \\
N: 23 \\
N(\%)\end{array}$ & $\begin{array}{l}\text { Non De- } \\
\text { hydrated } \\
\text { N:65 } \\
\text { N(\%) }\end{array}$ & OR & $\begin{array}{l}\text { IC } \\
(95 \%)\end{array}$ & \begin{tabular}{|l}
$P$ \\
value
\end{tabular} \\
\hline $\begin{array}{l}\text { Bronchi- } \\
\text { olitis }\end{array}$ & $47(53.4)$ & $10(43.4)$ & $37(56.9)$ & 0.5 & $0.1-1.6$ & 0.2 \\
\hline $\begin{array}{l}\text { Pneumo- } \\
\text { nia }\end{array}$ & $16(18.8)$ & $7(30.4)$ & $9(13.8)$ & 2.7 & $0.7-9.6$ & 0.07 \\
\hline Asthma & $12(12.6)$ & $1(4.3)$ & 11(16.9) & 0.2 & $\begin{array}{l}0.004- \\
1.7\end{array}$ & 0.1 \\
\hline $\begin{array}{l}\text { Recur- } \\
\text { rent } \\
\text { Wheez- } \\
\text { ing }\end{array}$ & $10(11.3)$ & $7(17.3)$ & $6(9.3)$ & 2 & $0.3-9.7$ & 0.2 \\
\hline IVRI & $2(2.2)$ & $1(4.3)$ & $1(1.5)$ & 2.9 & $\begin{array}{l}0.3- \\
231\end{array}$ & 0.4 \\
\hline Croup & $1(1.1)$ & - & $1(1.5)$ & - & - & 0.5 \\
\hline
\end{tabular}

Table 5: Diagnosis of patients admitted with lower respiratory tract infections according to hydration status.

\section{Discussion}

Dehydration is a common finding in patients attending to a Pediatric ED with respiratory and gastrointestinal diseases. Our study found that hydration status is not commonly evaluated on admission and a quarter of the patients had dehydration according to the CDS scale. Even if it's difficult to assess the weight change in the initial presentation this continue to be the gold standard to diagnoses dehydration. This study reveals that dehydration in this group of pathologies has to be suspect in the initial presentation to the ED. The main conclusion of our study is that the physician in the ED has to suspect that a patient with LRTI, may also present with a degree of dehydration and have to be treated, there are very few reports in the literature in regard to the relationship between LRTIs and dehydration. Most of the articles in children in relation with dehydration are related with acute gastroenteritis A study published in 1986 in Costa Rica that described the degree of dehydration based on clinical findings in relationship with respiratory infections $[7,8]$. The study included 140 patients that were admitted with LRTI and 26.4\% had a degree of dehydration. Eighty one percent of the dehydrated patients had normal serum electrolytes and the rest mild hyponatremia. In our study there was a prevalence of dehydration of $26.2 \%$ similar to the previous reported in the study (26.4\%) [9]. we used the CDS scale developed in Canada and weight change considered the gold standard to estimate dehydration [4, $7 \& 10]$. Weight gain after rehydration and IV fluids was used to measure percentage of dehydration. We decided to use the initial weight in ED and 24 hours after admission, because the study of Gorelick et al showed that the median time to achieve a stable weight was 24 hours for patients that were admitted to hospital [4]. In the study we determined that the prevalence of dehydration based on CDS scale was $26.1 \%$ of the population and we found that $55.6 \%$ had a weight change after 24 hours of admission. This study shows that the clinical based dehydration scale underestimated the degree of dehydration in patients with LRTIs when compared with weight change. Meta-analysis has showed that there is a limitation in regard to the clinical scales and reported that no single scoring system is better and that they will miss children with mild dehydration. All of them were done in patients with acute gastroenteritis $[3,11 \& 12]$. In the study of Mohs et al, the majority of the dehydrated patients were younger than 3 months compared with our study. In regards to past medical history, we did not found any association with the degree of dehydration and any of the documented morbidity [9]. The most common diagnosis in patients included in the study was bronchiolitis (47 (53.4\%)), followed by bronchopneumonia (16(18.8\%)); this result was expected because of the age group included in the study. We did not found any relationship with the degree of dehydration and the diagnosis of the patients. Schuh et al showed that the prevalence of dehydration in patients with bronchiolitis treated with evidence-based supportive therapies was $24 \%$. In our study $21.1 \%$ of patients with bronchiolitis had a degree of dehydration according to the CDS scale [13]. During the initial evaluation the presence of symptoms and signs such as vomiting, sunken eyes and poor oral intake, were highly associated with dehydration ( $\mathrm{p}=0.002)$, but we did not 
find anyassociation between thesesymptomsand severity of illness. Electrolytes were not measured in all patients $(52.2 \%)$, raising the possibility that some children had undiagnosed abnormal electrolytes. A limitation of the study was that patients with hyponatremia did not have electrolytes control 24 hours after the admission. We did not find any difference between patients with and without dehydration in regard to hospital stay, intensive care admission and complications related to the illness $[14,15]$. Treatment was not significantly different between dehydrated patients versus non-dehydrated according to final diagnosis. The only treatment that was significantly different was the use of rehydration fluids in $26.1 \%$ of the patients with any degree of dehydration. The decision to administered rehydration fluids is not a common practice in patients with LRTIs and is likely that if we decided to apply the CDS scale in this population we might increase the use of this treatment. This study had some limitations. The sample size was small, and we analyzed information from a single center. We included patients only during weekdays from $7 \mathrm{am}$ to $3 \mathrm{pm}$ where we had research assistant and during the months of the study we had a small number of patients with LRTI compared with other years that could affected the sample size. Another limitation is that the estimation of the degree of dehydration was a subjective evaluation of the physician in charge of the patient and this could underestimate it. All the patients in the initial management got their weight measured from the same scale in the ED, but the second measurement 24 hours after admission was not in the same weight scale and this could affect the final real weight change of the patients.

\section{Conclusions}

This is one of the few studies of dehydration in illness not related to gastroenteritis. The key finding of this study was that lower respiratory tract infections in some of the patients were associated with certain degree of dehydration. Not all patients with dehydration were detected using clinical findings and this difference was found using the weight change. Further studies are needed to validate the clinical dehydration scores in patients with respiratory tract infections.

Conflict of Interest: There are no conflicts of interest to declare this research did not receive any specific grant from funding agencies in the public, commercial, or not-for-profit sectors.

\section{References}

1. Nohynek H, Madhi S, Grijalva CG (2009) Childhood bacterial respiratory diseases: past, present, and future. Pediatr Infect Dis J 28: 127-132.

2. Nager AL, Wang VJ (2010) Comparison of ultrarapid and rapid intravenous hydration in pediatric patients with dehydration. Am J Emerg Med 28: 123-129.

3. Falszewska A, Szajewska H, Dziechciarz P (2018) Diagnostic accuracy of three clinical dehydration scales: a systematic review. Arch Dis Child 103: 383-388.

4. Gorelick MH, Shaw KN, Murphy KO (1997) Validity and reliability of clinical signs in the diagnosis of dehydration in children. Pediatrics 99: 6 .

5. Pringle K, Shah SP, Umulisa I, Mark Munyaneza RB, Dushimiyimana JM, et al. (2011) Comparing the accuracy of the three popular clinical dehydration scales in children with diarrhea. Int J Emerg Med 4: 58. 6. Friedman JN, Goldman RD, Srivastava R, Parkin PC (2004) Development of a clinical dehydration scale for use in children between 1 and 36 months of age. J Pediatr 145: 201-207.

7. Wathen JE (2004) Usefulness of the Serum Electrolyte Panel in the Management of Pediatric Dehydration Treated With Intravenously Administered Fluids. Pediatrics 114: 1227-1234.

8. Pelletier AJ, Mansbach JM, Camargo CA Jr (2006) Direct medical costs of bronchiolitis hospitalizations in the United States. Pediatrics 118: 2418-2423.

9. Colletti JE, Brown KM, Sharieff GQ, Barata IA, Ishimine P, Committee APEM (2010) The management of children with gastroenteritis and dehydration in the emergency department. J Emerg Med 38: 686-698.

Copyright:@2020 Adriana yock-corrales. This is an open-access article distributed under the terms of the Creative Commons Attribution License, which permits unrestricted use, distribution, and reproduction in any medium, provided the original author and source are credited. 